ORIGINAL ARTICLE

\title{
Haematological effect of iron supplementation in breast fed term low birth weight infants
}

\author{
D Aggarwal, H P S Sachdev, J Nagpal, T Singh, V Mallika
}

Arch Dis Child 2005;90:26-29. doi: 10.1136/adc.2003.040410

See end of article for authors' affiliations

....................

Correspondence to: Prof. H P S Sachdev, E-6/ 12. Vasant Vihar, New Delhi-110 057, India; hpssachdev@hotmail.com

Accepted 26 April 2004

\begin{abstract}
Aims: To determine the haematological effects of iron supplementation in predominantly breast fed term low birth weight (LBW) infants.

Methods: Seventy three healthy term LBW $(<2500 \mathrm{~g})$, predominantly breast fed infants aged 50-80 days were randomised into two groups to receive either iron ( $3 \mathrm{mg} / \mathrm{kg} /$ day) (iron supplemented (IS) group; $n=37$ ) or placebo drops (placebo $(P)$ group; $n=36$ ). Haematological parameters and anthropometry were measured at baseline and repeated after four and eight weeks.

Results: A total of 62 subjects ( 32 in the IS group and 30 in the P group) came for the first follow up and 26 (13 in the IS group and 13 in the P group) reported for the second visit. There were no significant differences in serum ferritin and anthropometry. However, covariates (infant age, haemoglobin, and ferritin, and maternal haemoglobin) adjusted haemoglobin change was significantly higher in the IS group after four weeks (4.6 g/l; $95 \% \mathrm{Cl} 0.5$ to 8.8) and eight weeks $(8.6 \mathrm{~g} / \mathrm{l} ; 95 \% \mathrm{Cl} 1.8$ to 15.4$)$.

Conclusions: Iron supplementation in a therapeutic dose in term breast fed LBW infants results in a marginal increase in haemoglobin. The functional benefit of this haemoglobin rise requires further evaluation.
\end{abstract}

$\mathrm{L}$ ow birth weight (LBW) infants have diminished iron reserves and are at greater risk of developing iron -deficiency. ${ }^{1}$ Based on data from developed countries, ${ }^{2}$ iron supplementation is recommended in LBW infants from 2 months of age. ${ }^{3}$ However, in developing countries two thirds of LBW infants are born at full term but are growth retarded. ${ }^{4}$ Since iron transfer is believed to be related to gestational age, and similar iron nutriture has been shown in small for gestational age (SGA) and appropriate for gestational age (AGA) babies, ${ }^{5}$ the utility of iron supplementation in all breast fed LBW infants is questionable. Considering the paucity of relevant trials we evaluated the haematological utility of iron supplementation in predominantly breast fed term LBW young infants.

\section{SUBJECTS AND METHODS}

This double blind randomised controlled trial was conducted at a tertiary hospital in New Delhi, India from April 1998 to February 1999. Seventy three consecutive apparently healthy predominantly breast fed (occasional water with breast feed) infants were recruited from the neonatal follow up clinic with informed parental consent and approval of the institutional committee. These infants were 50-80 days old, were of LBW $(<2500 \mathrm{~g})$, and were born at term ( $\geqslant 37$ weeks' gestation). Exclusion criteria were: twinning, congenital malformations, past blood transfusion, adverse neonatal events requiring hospitalisation, past blood sampling $(>10 \mathrm{ml})$, receiving iron supplementation, significant current morbidity, and maternal antepartum haemorrhage.

At recruitment, the subjects were randomised using computer generated random numbers (fig l). Infants in the iron supplemented (IS) group received iron drops (ferric ammonium citrate $25 \mathrm{mg} \mathrm{Fe} / \mathrm{ml}$ ). The $\mathrm{P}$ group received a placebo solution identical in dose, colour, and taste. All infants were called for follow up after four and eight weeks and advised to continue predominant breast feeding during this period. Compliance to supplementation was verified by maintenance of a home diary. Evaluation at baseline, and first and second follow ups included infant haemoglobin, peripheral smear, serum ferritin, and anthropometry. Haemoglobin was measured by the Hemocue system (validated in earlier trials ${ }^{6}$ ). Serum ferritin was estimated by ELISA. $^{7}$

The primary outcome variable was the infants' haemoglobin. Based on earlier data from this institution in this age group, it was estimated that 25 infants/group are required to evaluate a haemoglobin difference of $10 \mathrm{~g} / \mathrm{l}$ between the two groups with $95 \%$ confidence and $80 \%$ power (35 infants/ group were recruited to account for attrition). The post-trial estimates indicated that at four weeks the study had $95 \%$ confidence and $80 \%$ power to detect a difference of $7.5 \mathrm{~g} / \mathrm{l}$ of haemoglobin.

Serum ferritin was log converted to normalise the data. Student's $t$ test, $\chi^{2}$ test, Fisher's exact test, Mann-Whitney ranking test, and multiple linear regression were used wherever applicable.

\section{RESULTS}

Seventy three infants were enrolled (37 in the IS group; 36 in the P group). At first follow up 62 infants ( 32 in the IS group; 30 in the P group) reported while at second follow up only 26 infants ( 13 in each group) were available (fig 1). Infants lost to follow up at four weeks were comparable with those reporting for follow up except for lower baseline $\mathrm{Hb}$ (106 (7) $\mathrm{g} / \mathrm{l} v 116(12) \mathrm{g} / \mathrm{l} ; \mathrm{p}=0.013)$. However, the baseline infant $\mathrm{Hb}$ in these infants was comparable in the IS $(\mathrm{n}=5)$ and $\mathrm{P}$ groups $(n=6)$. Baseline characteristics for subjects who reported at four weeks were also comparable (table 1).

Infant haemoglobin levels were higher in the IS group at second follow up $(p=0.03)$, while serum ferritin and peripheral smear status were comparable $(p>0.05)$ at both follow ups (table 2). An analysis of the change in outcome parameters revealed that at the first follow up, the IS group had the mean haemoglobin advantage (unadjusted) of $5.3 \mathrm{~g} / \mathrm{l}$

Abbreviations: AGA, appropriate for gestational age; IS, iron supplemented; LBW, low birth weight; P, placebo; SGA, small for gestational age 


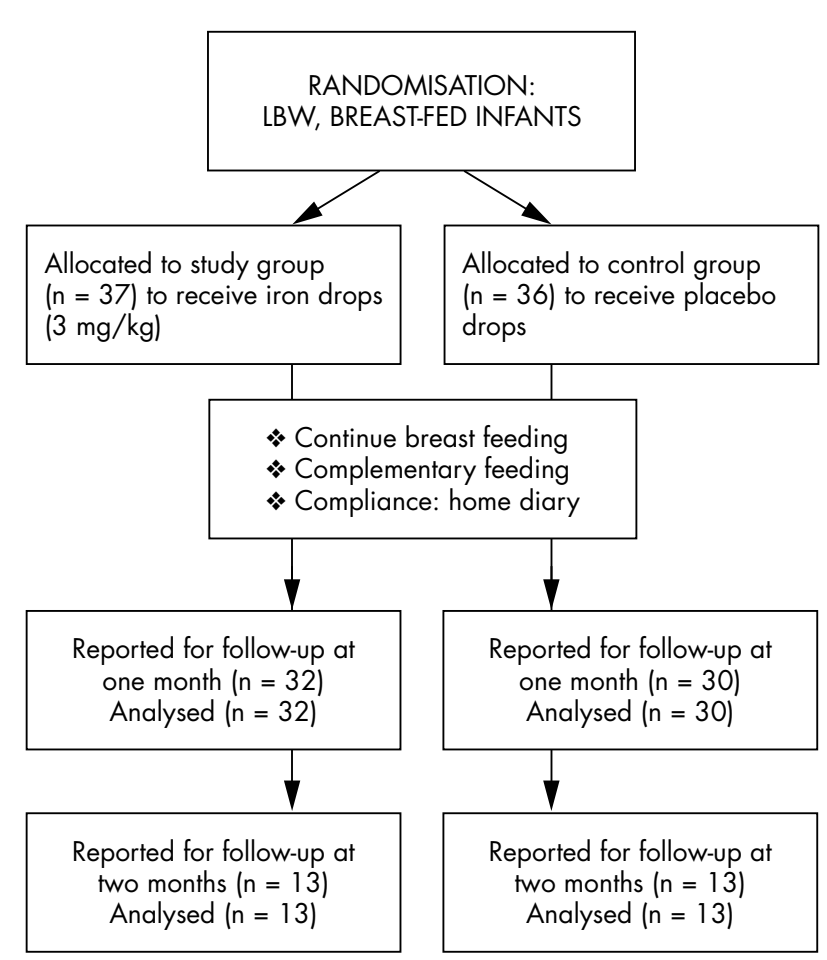

Figure 1 Summary of study design.

( $95 \%$ CI 0.2 to $10.5 \mathrm{~g} / \mathrm{l} ; \mathrm{p}=0.042$ ). This difference was $8.2 \mathrm{~g} / \mathrm{l}$ at second follow up $(\mathrm{p}=0.062)$. No significant differences were documented for other parameters.

At first follow up the adjusted (infant age, haemoglobin, and ferritin, and maternal ferritin) advantage in haemoglobin was $4.6 \mathrm{~g} / \mathrm{l}(95 \% \mathrm{CI} 0.5$ to $8.8 \mathrm{~g} / \mathrm{l} ; \mathrm{p}=0.024)$ in the IS group compared to the $\mathrm{P}$ group. At second follow up the corresponding figure was $8.6 \mathrm{~g} / \mathrm{l} \quad(95 \%$ CI 1.8 to 15.4 ; $\mathrm{p}=0.016)$.

Only two infants in the iron supplemented group reported mild vomiting, but drops were continued (table 3). The combined morbidity (at both follow ups) in the IS group was higher but not statistically significant $(p=0.078)$. Iron supplemented infants reported black stools in a significantly higher proportion $(\mathrm{p}<0.001)$.

\section{DISCUSSION}

Our results indicate that iron supplementation in a therapeutic dose in breast fed term LBW infants resulted in marginal improvement in haemoglobin status at one month $(4.6 \mathrm{~g} / \mathrm{l})$ and two months $(8.6 \mathrm{~g} / \mathrm{l})$ of follow up. Similar data

\section{What is already known on this topic}

- On the basis of data from developed countries, iron supplementation is recommended in low birth weight (LBW) infants from about 2 months of age

- In developed countries, the overwhelming majority of LBW infants are preterm, whereas in the developing world, the great majority of LBW infants are born at term but are intrauterine growth retarded

- Materno-fetal iron transfer is related to gestational duration; the need for iron supplementation in term breast fed LBW infants requires scientific validation
Table 1 Comparison of baseline characteristics

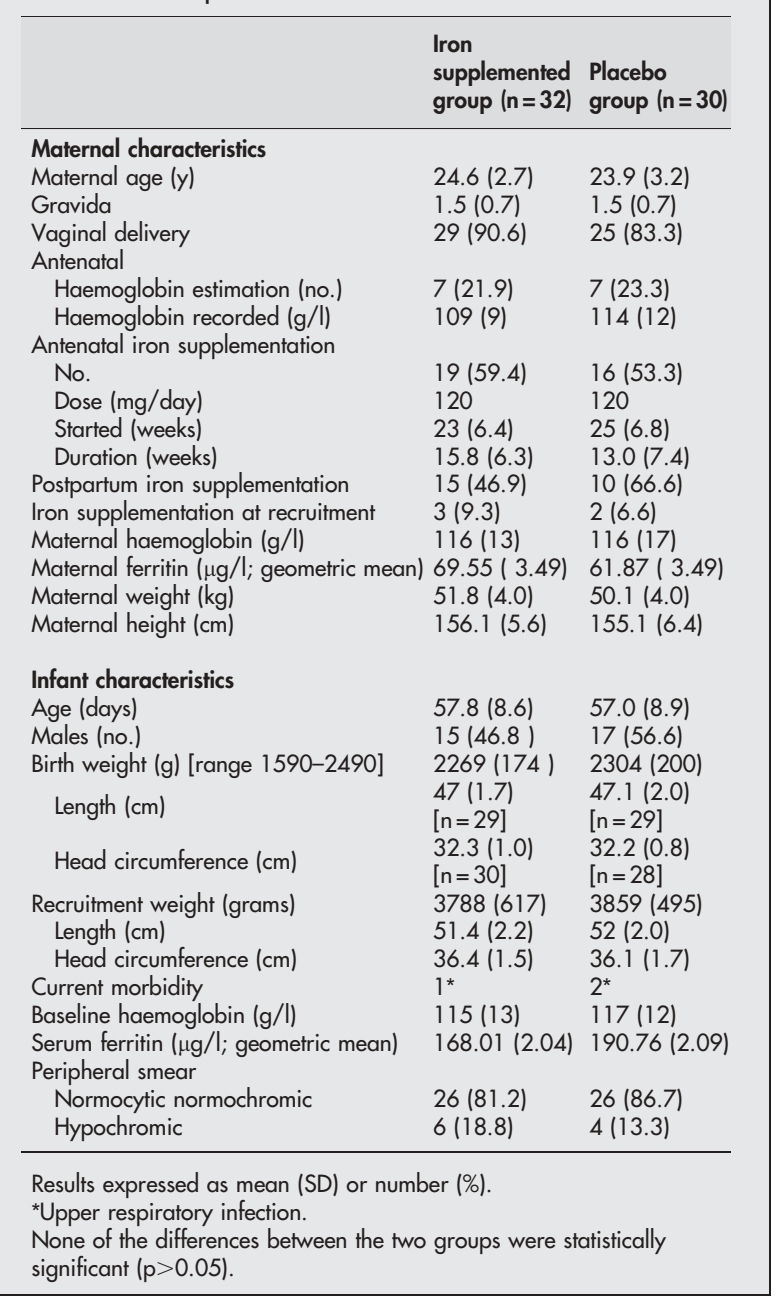

for comparison in breast fed term LBW infants is scarce. In an earlier supplementation trial from Chile, ${ }^{8}$ in 38 full term SGA infants, 15 subjects received iron $(3 \mathrm{mg} / \mathrm{kg} /$ day) from 2 to 4 months of age with no effect on the haemoglobin levels at 4 months of age. However, this study was not blinded (placebo not administered to controls) and all subjects were not predominantly breast fed. Comparative data in preterm infants indicates an improvement in haemoglobin with iron supplementation (average benefit after two to six months is $\left.7-11 \mathrm{~g} / \mathrm{l}^{359^{10}}\right)$. However, these studies either did not ensure the continuance of exclusive breast feeding, ${ }^{9}{ }^{10}$ or details of feeding were not available. ${ }^{3}$

There is considerable confusion regarding the dose, timing, and duration of iron supplementation practiced for LBW infants even in developed countries. Guidelines ${ }^{11}{ }^{12}$ are related to preterm infants and do not clarify the policy for term LBW infants. We used a dose of $3 \mathrm{mg} / \mathrm{kg}$ as the prevalence of anaemia was expected to be high.

There was no effect on serum ferritin after one or two months of supplementation in our study. The earlier study in

\section{What this study adds}

- Iron supplementation in a dose of $3 \mathrm{mg} / \mathrm{kg}$ in term breast fed LBW infants results in a marginal benefit in haemoglobin (4.6-8.6 g/l) 
Table 2 Comparison of the outcome measures at follow up visits

\begin{tabular}{|c|c|c|c|c|c|c|c|c|}
\hline & \multirow{2}{*}{$\begin{array}{l}\text { Haemoglobin } \\
\text { (g/l) }\end{array}$} & \multirow{2}{*}{$\begin{array}{l}\text { Serum ferritin } \\
(\mu \mathrm{g} / \mathrm{dl})^{*}\end{array}$} & \multicolumn{3}{|c|}{ Peripheral smear } & \multirow{2}{*}{$\begin{array}{l}\text { Head } \\
\text { circumference } \\
(\mathrm{cm})\end{array}$} & \multirow[b]{2}{*}{ Weight (g) } & \multirow[b]{2}{*}{ Length $(\mathrm{cm})$} \\
\hline & & & $\mathrm{NCHC}$ & MCHC & NCNC & & & \\
\hline \multicolumn{9}{|c|}{ INFANTS AVAILABLE AT FIRST FOLLOW UP ( $n=62$ ) } \\
\hline IS group $(n=32)$ & $114 \pm 9$ & $108.0 \pm 2.3$ & $5(15.6)$ & $1(3.1)$ & $26(81.25)$ & $38.5 \pm 1.6$ & $4663 \pm 535$ & $54.4 \pm 2.3$ \\
\hline$P$ group $(n=30)$ & $110 \pm 11$ & $124.1 \pm 2.5$ & $6(20.0)$ & $1(3.3)$ & $23(76.7)$ & $38.4 \pm 1.8$ & $4771 \pm 469$ & $54.9 \pm 2.2$ \\
\hline Mean difference & 3.6 & _- & - & - & _- & $0.12^{-}$ & -108 & $-0.4 \overline{8}$ \\
\hline$(95 \% \mathrm{Cl})$ & $(-1.7$ to 8.4$)$ & - & & & & $(-0.7$ to 1.0$)$ & $(-364$ to 148$)$ & $(-1.6$ to 0.6$)$ \\
\hline$p$ value & 0.19 & 0.356 & 0.950 & & & 0.700 & 0.954 & 0.398 \\
\hline \multicolumn{9}{|c|}{ Change in outcome measures from baseline to first follow up } \\
\hline IS group $(n=32)$ & $-1.4 \pm 11$ & $-64.2 \pm 91.2$ & - & & & $2.1 \pm 0.6$ & $875.7 \pm 282.7$ & $3.0 \pm 1.1$ \\
\hline$P$ group $(n=30)$ & $-6.8 \pm 9$ & $-65.0 \pm 119.8$ & - & & & $2.3 \pm 0.7$ & $912.3 \pm 224.0$ & $3.0 \pm 1.3$ \\
\hline Mean difference & 5.3 & 0.78 & _- & & & $-0 . \overline{1} 7$ & -36.7 & $0.0 \overline{5}$ \\
\hline$(95 \% \mathrm{Cl})$ & $(0.2$ to 10.5$)$ & $(-53.1$ to 54.6$)$ & - & & & $(-0.48$ to 0.14$)$ & $(-166.8$ to 93.4$)$ & $(-0.54$ to 0.64$)$ \\
\hline$p$ value & 0.042 & 0.274 & - & & & 0.280 & 0.575 & 0.871 \\
\hline \multicolumn{9}{|c|}{$\begin{array}{l}\text { INFANTS AVAILABLE AT SECOND FOLLOW UP }(n=26) \\
\text { Outcome measures at second follow up }\end{array}$} \\
\hline IS group $(n=13)$ & $117 \pm 9$ & $83.8 \pm 2.0$ & $4(30.7)$ & $1(7.7)$ & $8(61.5)$ & $40.5 \pm 1.8$ & $5669 \pm 475$ & $58.9 \pm 2.9$ \\
\hline$P$ group $(n=13)$ & $107 \pm 12$ & $88.4 \pm 2.6$ & $3(23.1)$ & $1(7.7)$ & $9(69.2)$ & $40.9 \pm 2.1$ & $5523 \pm 370$ & $57.3 \pm 2.0$ \\
\hline Mean difference & 9.8 & - & - & - & - & -0.238 & 148 & 1.6 \\
\hline$(95 \% \mathrm{Cl})$ & (0.9 to 18.9$)$ & - & - & - & & $(-1.8$ to 1.3$)$ & $(-199$ to 491$)$ & $(-0.4$ to 3.5$)$ \\
\hline$p$ value & 0.03 & 0.681 & 0.736 & & & 0.310 & 0.390 & 0.108 \\
\hline \multicolumn{9}{|c|}{ Change in outcome measures from baseline to second follow up } \\
\hline IS group $(n=13)$ & 1.4 & -121.1 & - & & & $3.8 \pm 1.0$ & $1684.6 \pm 535$ & $6.6 \pm 2.1$ \\
\hline P group $(n=13)$ & -6.8 & -111.3 & - & & & $4.5 \pm 1.4$ & $1653.8 \pm 260$ & $5.2 \pm 1.3$ \\
\hline Mean difference & 8.2 & -9.61 & _- & & & $-0 . \overline{7} 5$ & $30.7-6$ & $-1 . \overline{3} 3$ \\
\hline$(95 \% \mathrm{Cl})$ & $(-0.4$ to 16.8$)$ & $(-113$ to 94$)$ & - & & & $(-1.76$ to 0.26$)$ & $(-310$ to 371$)$ & $(-0.07$ to 2.73$)$ \\
\hline \multicolumn{9}{|c|}{ Adjusted $†$ change in infant haemoglobin } \\
\hline Variable & b & SE (b) & \multicolumn{3}{|c|}{$95 \% \mathrm{Cl}$ for $\mathrm{b}$} & p value & $\mathbf{R}^{2}$ & F-test: \\
\hline \multicolumn{9}{|l|}{ First follow up $(n=62)$} \\
\hline $\begin{array}{l}\text { Group } \\
(0=\text { iron, } 1=\text { placebo }) \\
\text { Second follow up }(n=2\end{array}$ & 26) 4.66 & 2.07 & \multicolumn{3}{|c|}{0.052 to 0.880} & 0.024 & 0.471 & $<0.001$ \\
\hline $\begin{array}{l}\text { Group } \\
(0=\text { iron, } 1=\text { placebo })\end{array}$ & 8.60 & 3.25 & \multicolumn{3}{|c|}{0.180 to 1.540} & 0.016 & 0.582 & 0.003 \\
\hline \multicolumn{9}{|c|}{$\begin{array}{l}\text { Results expressed as mean } \pm S D \text { or number }(\%) \text {. } \\
\text { *Means indicated are geometric means except those depicted under change in outcome measures (arithmetic means). } \\
\text { tThe change in haemoglobin has been adjusted for infant age, infant baseline haemoglobin, infant ferritin, and maternal haemoglobin. } \\
\text { Calculated by Mann-Whitney ranking test. } \\
b \text { is the regression coefficient, SE (b) is the standard error of b. } \\
\text { IS group, iron supplementation group; P group, placebo group. } \\
\text { MCHC, microcytic hypochromic; NCHC, normocytic hypochromic; NCNC, normocytic normochromic. }\end{array}$} \\
\hline
\end{tabular}

term SGA infants also reported similar findings. ${ }^{10}$ Some preterm trials documented a significant improvement in serum ferritin, ${ }^{13}$ whereas others had no significant change or did not estimate ferritin. ${ }^{9}{ }^{10}$

Table 3 Comparison of reported side effects and morbidity experienced in the two groups at follow up

\begin{tabular}{|c|c|c|}
\hline Side effect/morbidity & $\begin{array}{l}\text { Iron supplemented } \\
\text { group }\end{array}$ & Placebo group \\
\hline $\begin{array}{l}\text { First follow up } \\
\text { Vomiting } \\
\text { Black stools* } \\
\text { Current morbidity } \\
\text { Interval morbidity }\end{array}$ & $\begin{array}{l}(n=32) \\
2(6) \\
22[69] \\
0 \\
6(19)\end{array}$ & $\begin{array}{l}(n=30) \\
0 \\
0 \\
0 \\
1(3)\end{array}$ \\
\hline $\begin{array}{l}\text { Second follow up } \\
\text { Vomiting } \\
\text { Black stools* } \\
\text { Current morbidity } \ddagger \\
\text { Interval morbidity }\end{array}$ & $\begin{array}{l}(n=13) \\
0 \\
9[28] \\
1(3) \\
3(9)\end{array}$ & $\begin{array}{l}(n=13) \\
0 \\
0 \\
0 \\
2(7)\end{array}$ \\
\hline \multicolumn{3}{|c|}{$\begin{array}{l}\text { Results expressed as number (\%). } \\
\text { *p value }<0.001 \text {. } \\
\text { †All interval morbidity was upper respiratory infection except for } \\
\text { bronchiolitis in one iron supplemented infant at one month follow up. } \\
\text { fUpper respiratory infection. }\end{array}$} \\
\hline
\end{tabular}

We did not document any benefit in anthropometry; the inadequate duration of follow up and small sample size however preclude any definite conclusions. The earlier trials have not reported on these outcome measures. The morbidity experience of the two groups was comparable, which is in consonance with the findings of a recent systematic review. ${ }^{14}$

In conclusion, iron supplementation in a therapeutic dose in term breast fed LBW infants results in marginal benefit in haemoglobin (4.6-8.6 g/l). These preliminary data would prove useful for designing future trials on larger sample sizes and longer follow ups to evaluate: (1) functional consequences of iron supplementation apart from haematological parameters, including mental and motor development, infections, and anthropometry; (2) utility of prophylactic dosing ( $1-2 \mathrm{mg} / \mathrm{kg}$ ); and (3) role of selective supplementation in initially anaemic infants.

\section{Authors' affiliations}

D Aggarwal, H P S Sachdev, J Nagpal, Division of Clinical Epidemiology, Department of Pediatrics, Maulana Azad Medical College, New Delhi 110 002, India

T Singh, Division of Clinical Epidemiology, Department of Pathology, Maulana Azad Medical College, New Delhi 110 002, India

V Mallika, Department of Biochemistry, G.B. Pant Hospital, New Delhi 110002 , India 
Funding: The iron supplements and placebo solutions were donated by a pharmaceutical house not manufacturing iron drops

\section{REFERENCES}

1 Dallman PR. Iron deficiency anemia: a synthesis of current scientific

knowledge and U.S. recommendation for prevention and treatment. In: Iron deficiency anemia, recommended guideline for the prevention, detection and management among U.S. children and women of child bearing age. Institute of Medicine, Washington, DC: National Academy Press, 1993:41-96.

2 Lundstrom U, Siimes MA, Dallman PR. At what age does iron supplementation become necessary in low birth weights? J Pediatr 1997;99:878-83.

3 UNICEF/WHO, Joint Committee on Health Policy. Strategic approach to operationalizing selected end decade goals: reduction of iron deficiency anemia, JCHP30/96/4.5, 1995.

4 Sachdev HPS. Low birth weight in South Asia. In: Gillespie SR, ed. Malnutrition in South Asia: a regional profile. ROSA Publication no. 5. Kathmandu, Nepal: UNICEF Regional Office for South Asia, 1997:23-50.

5 Scott PH, Berger HM, Kenward C, et al. Effect of gestational age and intrauterine nutrition on plasma transferrin and iron in the newborn. Arch Dis Child 1975;50:796-8.

6 Lardi AM, Hirst C, Mortimer AJ, et al. Evaluation of Hemocue for intraoperative hemoglobin concentrations: a comparison with Coulter Max M. Anaesthesia 1998;53:349-52.
7 Renenant MC. Sandwich enzyme immunoassay for ferritin with polypropylene test tubes as the solid phase. Clin Chem 1983;29:681-3.

8 Olivares M, Elaguno S, Marin V, et al. Iron status in low birth weight infants, small and appropriate for gestational age. A follow up study. Acta Pediatr 1992;81:824-8.

9 Brozovic B, Burland WL, Simpson K, et al. Iron status of low birth weight infants and their response to oral iron. Arch Dis Child 1974:49:385-9.

10 Jansson L, Holmberg I, Ekman R. Medicinal iron to low birth weight infants. Acta Pediatr Scand 1979;68:705-8.

11 World Health Organisation. Complementary feeding of young children in developing countries: a review of current scientific knowledge, WHO/NUT/ 98.1. Geveva, World Health Organisation, 1998.

12 Earl RO, Woteki CE, Institute of Medicine Committee on the Prevention, Detection, and Management of Iron Deficiency Anemia among U. S. Children and Women of Childbearing Age. Iron deficiency anemia: recommended guidelines for the prevention, detection, and management among U.S. children and women of childbearing age. Washington, DC: National Academy Press, 1993.

13 Barclay SM, Aggett PJ, Lloyd DJ, et al. Reduced erythrocyte superoxide dismutase activity in low birth weight infants given iron supplements. Pediatr Res 1991;29:297-301.

14 Gera T, Sachdev HPS. Effect of iron supplementation on incidence of infectious illness in children: systematic review. BMJ 2002;325:1142-4.

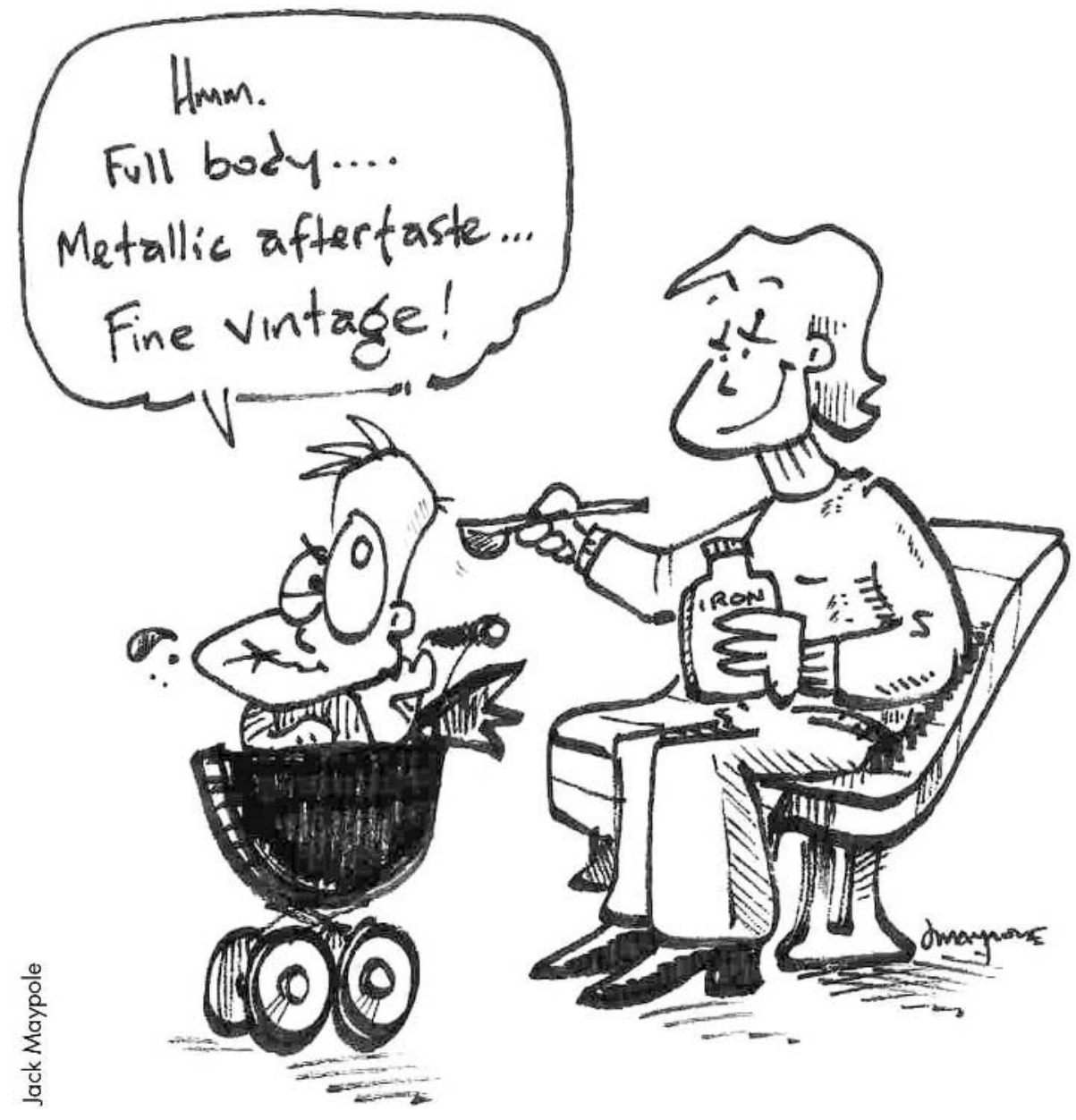

